\title{
Improving the quality of university education in Sri Lanka: an analysis of Quality Assurance Agency Council's reviews
}

\author{
Chandra Gunawardena* \\ Emeritus Professor in Education, The Open University of Sri Lanka, Nawala, Sri Lanka.
}

\begin{abstract}
Knowledge economy requires institutions with the ability to discover new knowledge, develop innovative applications of these discoveries and transfer them into the marketplace through entrepreneurial activities. Knowledge accumulation is increasingly at the core of a country's competitive advantage. In Sri Lanka, during the last two decades, increasing concern has been expressed about the quality of university education. The World Bank (2009) reiterated that the establishment of a Quality Assurance System for the full higher education sector is of great importance. The Quality Assurance Agency Council of the University Grants Commission, Sri Lanka (QAAC) was established in 2007 to review programmes of study offered by various Departments of Study (Subject Reviews) and the quality of higher education institutions (Institutional Reviews). This paper analyses the institutional and subject review reports submitted for the state universities by the Quality Assurance Agency Council of Sri Lanka to identify key issues that the universities need to take up in order to assure quality. Overall, institutional reviews portray a positive scenario with the majority of the universities being on the way to improve their quality. Analysis of the Subject Review Reports indicate that, on the whole, the Departments in universities have performed satisfactorily, obtaining Good grades for half the courses and Satisfactory grades for $41 \%$ of courses. Eight Universities have received a higher percentage of Good grades for their courses. However, in some aspects directly impinging on teaching-learning, performance of some of the Departments has been adjudged to be Unsatisfactory. It has to be recognised that External Reviews can contribute only to a certain extent to improve the quality. These Reviews need to be seriously discussed at Faculty Boards and Senates and progress monitoring be maintained if the desirable outcome is to be achieved.
\end{abstract}

Keywords: Knowledge Economy, Quality of university education in Sri Lanka, Institutional Reviews, Subject Reviews, Quality Assurance Agency Council.

\section{INTRODUCTION}

Knowledge economy demands a highly educated citizenry enabled by development of a strong system of education at all levels. It also requires institutions with the ability to discover new knowledge, develop innovative applications of these discoveries, and transfer them into the marketplace through entrepreneurial activities. Knowledge Economy ranking is the simple average of four sub-indexes: economic incentive and institutional regime; innovation and technological adoption; education and training; information and communications infrastructure. Out of 145 countries surveyed in 2012, Sri Lanka's ranking was 101, above all the other South Asian countries. A knowledge economy is characterised by close links between science and technology, greater importance placed on innovation for economic growth and competitiveness, increased significance of education, and life-long learning, and greater investment in intangibles such as R\&D and software.

In Sri Lanka, during the last two decades, increasing concern has been expressed about the quality of university education. The Presidential Task Force on University Education in 1997 pointed out that several factors such as (1) Expansion of facilities lagging far behind the increase of enrolments, (2) The loss resulting from the withdrawal of English as the medium of instruction which is debilitating, (3) The absence of an academically stimulating environment, (4) Widespread apathy among a majority of both staff and students and (5) Lectures degenerating into dictation had contributed to this situation. 
In what appears as a total indictment of university education, the Asian Development Bank (2000) stated

"On the whole, a rigid and outdated educational system persists anchored on outmoded teaching and learning methodologies, rote learning, lecture notes, traditional curricula and inadequately localized textbooks".

The World Bank (2009) reiterated that the establishment of a quality assurance system for the full higher education sector is of great importance and that,

"Sri Lanka needs quality assurance mechanisms covering the programs and courses in postgraduate education, undergraduate education, distance learning, and the private higher education sector. It underscored that the quality of higher education has to be substantially strengthened to produce graduates of international quality and research. The research and innovation capacity of the higher education system should be dramatically strengthened to support, and eventually lead the development of Sri Lanka as a MIC. The higher education sector will need to produce human resources for knowledgeintensive industries and services. The capacity for rapid technology adoption and adaptation, as well as innovation, will play a crucial role in development. In addition, close linkages need to be promoted between universities and industries."

The purpose of this paper is to analyse the institutional and subject review reports submitted for the state universities by the Quality Assurance Agency of Sri Lanka and identify key issues that the universities need to take up in order to assure quality. No attempt will be made to find out what action has been taken by individual universities to improve quality on the basis of these reviews.

\section{REVIEW OF PERTINENT LITERATURE}

The new Millennium has been described as an age of knowledge, in which the resource for prosperity has become knowledge itself. Today, the emphasis is shifting from creating and transporting physical objects to knowledge itself. Knowledge accumulation is increasingly at the core of a country's competitive advantage, which is itself determined by the ability to innovate in a continuous manner (Holm-Nielsen, 2009). Today, the world has entered a period of rapid and profound economic, social and political transformation driven by the emergence of a radically new system for creating wealth that depends upon the creation and application of new knowledge and hence upon educated people and their ideas" (Duderstadt, 2008).

In 1996, Clark stressed that the expansion and complexity in the knowledge with which universities now deal is one of the salient forces for change in higher education. Thus, "the driving force behind the $21^{\text {st }}$ Century economy is considered as knowledge and developing human capital as the best way to ensure prosperity" (National Conference of State Legislatures, 2006). Knowledge economy also requires institutions with the ability to discover new knowledge, develop innovative applications of these discoveries, and transfer them into the marketplace through entrepreneurial activities (Drucker, 2005). Knowledge produced in this manner can immediately or with little delay be disseminated to populations dispersed across the globe as a result of growing interconnectedness.

Department for Business Innovation and Skills (DBIS) (UK) (2008) pointed out that,

"In a knowledge economy, universities are the most important mechanism for generating and preserving, disseminating and transforming knowledge into wider social and economic benefits. They are crucial too, as the providers of life-chances to individuals in an environment where skills and the ability to apply those skills are essential for employment".

DBIS argues that a strong university system is essential to a country's economic success and the vibrancy and depth of its intellectual and cultural life.

The Graz Declaration on Committing Universities to Sustainable Development (2009) concluded that universities as the location of academic education, bear a distinctive responsibility for the students and their professional moral quality as future leaders in society and economy and as major contributors to research, they should tackle questions which rise in connection with the transition of societies around the world towards more sustainable development.

The university plays a particular set of roles in the global knowledge economy. It acts as a provider of both private and public goods in terms of education and research, as well as playing historically well-established roles in terms of applied problem-solving. The university also acts as a conduit for the wider societal impacts linked to and co-evolving with the other three roles and facilitating integration into the wider social and innovation system (Diaco et al., 2012). In order to perform the above stipulated goals, it is mandatory for universities in any country ensure quality in performing their functions. 


\section{SRI LANKA'S ATTEMPTS TO MEET CURRENT CHALLENGE OF QUALITY IN UNIVERSITY EDUCATION}

Three recent initiatives: the IRQUE (Improving Relevance and Quality of University Education) Project, the QAA (Quality Assurance Agency) initiative under the University Grants Commission and the Distance Education Modernization Project (DEMP) under the Ministry of Higher Education were attempts to address the need to improve relevance and quality. This paper will attempt to peruse the work of the QAAC and especially focus on the Reviews conducted by the QAAC.

The Quality Assurance Agency (QAA) was established in 2007 to review programmes of study offered by various Departments of Study (Subject Reviews) and the quality of higher education institutions (Institutional Reviews). By April, 2015, the Manual for Institutional Review of Sri Lankan Universities and Higher Educational Institutes which was developed by the QAA was approved by the University Grants Commission. In May, 2015, the Manual was launched. The Internal Quality Assurance Circular and IQA Manual were issued by the UGC in May, 2015.

IQA Manual emphasises the need for Quality Assurance in Universities and explains how external and internal quality assurance complements each other and that the self assessment report becomes a critical core element of the external quality assurance process. External quality assurance can play a very important role in strengthening internal quality assurance. Identification of the criteria used for external quality assurance can inform institutions of what they need to focus on in developing and strengthening their internal quality assurance processes.

\section{ANALYSIS OF REVIEW REPORTS}

\section{Institutional Review Reports}

The institutions reviewed by QAA were Open University, (2003), University of Peradeniya and University of Moratuwa (2006), University of Kelaniya, South-Eastern University and University of Visual \& Performing Arts (2009), University of Colombo (2010), and University of Ruhuna, Eastern University, Sabaragamuwa and Gampaha Wickramarachchi Ayurveda Institute (Gampaha WAI), Sri Jayewardenepura, Jaffna, Rajarata, Wayamba and Uva Wellassa Universities (2011). In the case of the University of Jaffna, even the First Review Report was not accessible. Second Reviews had also been carried out in 2013 of the Open University, University of
Moratuwa, South-Eastern University and Sabaragamuwa University but these were not available for perusal. These Second Review Reports would have been helpful to find out whether substantial progress had been achieved after the First Reviews.

The Institutional Reviews focused on the aspects of (1) University Goals and Corporate Planning, (2) Financial Resources and Management, (3) Research (4) Quality Management \& Administration, (5) Quality Assurance, (6) Learning Resources \& Student Support, (7) External Degree Programmes and (8) University/ Industry/Community and Other Extension Activities. Of the 15 institutions, except for South-Eastern University, University of Visual \& Performing Arts and Eastern University (which received Limited Confidence), others received Confidence in the overall evaluation. Table 1 summarises the evaluations given by Review Teams in relation to each aspect, categorising the universities under (A) Very Good (2) Good (C) Satisfactory and (3) Not Satisfactory.

Table 1 indicates that the only university which had performed well in all eight aspects was the University of Ruhuna. Specifically out of the eight aspects, Universities of Colombo, Sabaragamuwa and Gampaha WAI had each performed up to expectations on six; Sri Jayewardenepura and Kelaniya on five out of the eight aspects, Peradeniya, Rajarata and Wayamba on four aspects. Out of seven aspects, Uva-Wellassa and University of Moratuwa had performed satisfactorily on five aspects, Open University on three aspects and Visual and Performing Arts on two. Eastern University had not performed well even on one aspect. The aspect of External degrees was not relevant for the universities of Moratuwa, Open University and Visual \& Performing Arts.

Teaching is accepted as the core function of a university but in Learning Resources \& Student Support, six universities, (Moratuwa, Colombo, Open University, Eastern, South-Eastern and Visual \& Performing Arts), had not performed up to expectations.

Especially noteworthy is the fact that only seven universities (Moratuwa, Colombo, Kelaniya, Sri Jayewardenepura, Peradeniya, Ruhuna, Sabaragamuwa) had performed well in Research, a major function of universities, which enhances the quality of teaching and contributes to social and economic development of a country. If the knowledge economy requires institutions with the ability to discover new knowledge, to develop innovative applications of these discoveries and transfer them into the marketplace through entrepreneurial activities, it is imperative for Sri Lankan universities 
Table 1: Evaluation of universities under Institutional Reviews

\begin{tabular}{lllllllll}
\hline University & Aspect 1 & Aspect 2 & Aspect 3 & Aspect 4 & Aspect 5 & Aspect 6 & Aspect 7 & Aspect 8 \\
\hline Peradeniya & B & B & A & B & A & A & A & A \\
Colombo & A & A & A & B & A & B & A & A \\
Kelaniya & B & B & A & A & A & A & B & A \\
Sri Jayewardenepura & B & B & A & A & A & A & B & A \\
Moratuwa & A & B & A & A & A & B & NR & A \\
Ruhuna & A & A & A & A & A & A & A & A \\
Open University & A & A & B & B & B & B & NR & A \\
Sabaragamuwa & A & A & A & B & B & A & A & A \\
Rajarata & B & B & B & B & A & A & A & A \\
Eastern & B & B & B & B & B & B & A & B \\
South-Eastern & B & B & B & B & A & B & B & A \\
Wayamba & B & A & B & A & A & A & A & A \\
Uva-Wellassa & A & B & & A & A & A & NR & A \\
Visual \& & B & B & B & A & A & B & NR & B \\
GampahaWAI & B & A & B & A & A & A & A & A
\end{tabular}

to focus more on research and publications rather than become only teaching universities.

\section{Subject Reviews}

The Departments of Study were evaluated on 8 aspects. The eight aspects are:

(1) Curriculum design, content and review

(2) Teaching, Learning and Assessment Methods

(3) Quality of Students, including Student Progress and Achievement

(4) Extent and Use of Student Feedback: Qualitative and Quantitative

(5) Postgraduate Studies

(6) Peer Observation

(7) Skills Development

(8) Academic Guidance and Counselling.

Table 2 gives the performance of Universities according to the evaluation of different Departments by the Review Teams and the number of Departments which were given Grades of A, B and C. Grade A denoted Good, Grade B Satisfactory and Grade C Unsatisfactory. In the case of Medicine, in most Universities, the entire Faculty has been graded together on the eight aspects.
Table 2 shows that, on the whole, the Departments in universities have performed satisfactorily obtaining A grades for just more than half the courses $(52 \%)$ and B grades for $40 \%$ of the courses evaluated by the Review Teams. It is also relevant to note that while universities such as Moratuwa, Sri Jayewardenepura, Peradeniya, Kelaniya, Colombo, Ruhuna, Wayamba, Vavuniya Campus have been given a higher percentage of A grades, South-Eastern, Jaffna and Eastern Universities have been given less than $40 \%$ A grades. In contrast, while no $\mathrm{C}$ grades have been given to any of the Departments in the University of Moratuwa, in the Universities of Sri Jayewardenepura and Kelaniya also the percentages of $\mathrm{C}$ grades is lower than $1 \%$. Here it is noted that South-Eastern University and Eastern University, which had received Limited Confidence in the Institutional Reviews, had $17.9 \%$ and $14.3 \%$ Departments receiving $\mathrm{C}$ grades respectively, indicating a correspondence between Institutional and Subject Reviews.

It was considered pertinent to look at the subject reviews by Faculty/Discipline as there is a perception that some Faculties perform better than others. The comparison of the detailed performance of selected Faculties is given in Appendix (Table I) and a summary is presented in Table 3. The above table reveals that the number of Faculties providing higher education in different disciplines vary largely from 4 Faculties in Engineering to 11 in Management and related fields, 13 in Science and to 15 in Arts and related disciplines. The number of Departments also varies from 84 in Arts to 21 in Engineering. What is more important is to note that their performance varies from $79.8 \% \mathrm{~A}$ grades and 
Table 2: Performance of universities according to Subject Reviews

\begin{tabular}{|c|c|c|c|c|c|}
\hline University & $\begin{array}{l}\text { No. Depts. } \\
\text { evaluated }\end{array}$ & & Grades & & Total* \\
\hline & & A & $\mathrm{B}$ & $\mathrm{C}$ & \\
\hline Moratuwa & 15 & 101 & 19 & -- & 120 \\
\hline$\%$ & & 84.2 & 15.8 & -- & \\
\hline Sri Jayawardenapura & 36 & 187 & 92 & 9 & 288 \\
\hline$\%$ & & 64.9 & 31.9 & 0.3 & \\
\hline Peradeniya & 38 & 166 & 115 & 23 & 304 \\
\hline$\%$ & & 54.6 & 37.8 & 07.6 & \\
\hline Kelaniya & 30 & 128 & 99 & 13 & 240 \\
\hline$\%$ & & 53.3 & 41.3 & 0.5 & \\
\hline Colombo & 28 & 119 & 89 & 16 & 224 \\
\hline$\%$ & & 53.1 & 39.7 & 07.1 & \\
\hline Ruhuna & 25 & 105 & 83 & 12 & 200 \\
\hline$\%$ & & 52.5 & 41.5 & 06.0 & \\
\hline Sabaragamuwa & 13 & 51 & 42 & 11 & 104 \\
\hline$\%$ & & 49.0 & 40.4 & 10.6 & \\
\hline Wayamba & 16 & 64 & 52 & 12 & 128 \\
\hline$\%$ & & 50.0 & 40.6 & 09.3 & \\
\hline Vavuniya Campus & 4 & 16 & 12 & 4 & 32 \\
\hline$\%$ & & 50.0 & 37.5 & 12.5 & \\
\hline Open University & 18 & 68 & 68 & 8 & 144 \\
\hline$\%$ & & 47.2 & 47.2 & 06.0 & \\
\hline Rajarata & 10 & 32 & 39 & 9 & 80 \\
\hline$\%$ & & 40.0 & 48.8 & 11.0 & \\
\hline $\begin{array}{l}\text { South-Eastern Uni- } \\
\text { versity }\end{array}$ & 7 & 22 & 24 & 10 & 56 \\
\hline$\%$ & & 39.3 & 42.9 & 17.9 & \\
\hline Jaffna & 29 & 88 & 120 & 24 & 232 \\
\hline$\%$ & & 37.9 & 51.7 & 10.3 & \\
\hline Eastern University & 21 & 60 & 84 & 24 & 168 \\
\hline$\%$ & & 35.7 & 50.0 & 14.3 & \\
\hline Total No. of Depts. ** & 290 & 1207 & 938 & 175 & 2320 \\
\hline$\%$ & & 52.0 & 40.4 & 07.5 & \\
\hline
\end{tabular}

- No. of Departments by No. of Aspects.

** Some Faculties of Medicine reviewed together

$0.01 \% \mathrm{C}$ grades in Engineering to $45.2 \% \mathrm{~A}$ grades and $11 \% \mathrm{C}$ grades in Arts-related disciplines. This could be a cumulative effect of enrolling a lower number of students to some Departments and Faculties, which results in a better concentration of facilities and resources as well as students with higher performance at GCE (A/L) being admitted to them.

If remedial action is to be taken to improve performance, it is pertinent to inquire into the aspects in which the Departments of Study had been evaluated as Unsatisfactory (Appendix: Table I). A summary of the details is given in Table 4 .
Table 4 shows that none of Departments had been given $\mathrm{C}$ grades for the aspect, Quality of Students, including student progress \& achievement, which is commendable. At the same time, it is noted that except in the case of the Open University, students for undergraduate degrees are selected on the basis of their performance at GCE(A/L) Examination.

All universities need to be commended as except for the Departments in the Medical Faculty, University of Jaffna which have been evaluated as Unsatisfactory on the aspect of Teaching, Learning \& Assessment Methods; 
Table 3: Performance of selected Faculties according to Subject Reviews

\begin{tabular}{|c|c|c|c|c|c|}
\hline All Faculties (No.) & No. of Depts. evaluated & & Gra & & Total \\
\hline & & A & B & $\mathrm{C}$ & \\
\hline Engineering-related (4) & 21 & 134 & 33 & 1 & 168 \\
\hline$\%$ & & 79.8 & 19.6 & 0.01 & \\
\hline Science \& Related (13) & 65 & 299 & 195 & 34 & 528 \\
\hline$\%$ & & 56.6 & 36.9 & 06.4 & \\
\hline Medical (6) & 17 Depts. 4 Faculties & 83 & 74 & 11 & 168 \\
\hline$\%$ & & 49.4 & 44.0 & 06.5 & \\
\hline $\begin{array}{l}\text { Management \& Related } \\
\text { (11) }\end{array}$ & 43 & 163 & 158 & 23 & 344 \\
\hline$\%$ & & 47.4 & 45.9 & 0.7 & \\
\hline Agriculture- related (7) & 30 & 131 & 101 & 16 & 278 \\
\hline$\%$ & & 47.1 & 36.3 & 05.8 & \\
\hline Arts -related (15) & 84 & 307 & 291 & 74 & 672 \\
\hline$\%$ & & 45.2 & 43.3 & 11.0 & \\
\hline
\end{tabular}

other Universities and Faculties have received grades denoting satisfaction. Similarly, only two Departments in two Universities have been given $\mathrm{C}$ for the aspect, Curriculum Design, Content \& Review, which is a major function of any university. Eight Departments of Study in six Faculties in six Universities have been declared as Unsatisfactory in the aspect on Skills Development. Five of these eight Departments are in Arts-oriented Faculties. It is not possible to check whether the Reviewers had construed "Skills" as purely psycho-motor skills, without taking into consideration, other academic skills such as Communication, Planning and Organisation and Problem-solving and Decision-making which are indisputably "Skills" which need to be developed through University education.

In the case of "Extent \& Use of Student Feedback, Qualitative \& Quantitative", 18 Departments of Study, in 13 Faculties in 8 Universities have been given a $\mathrm{C}$ grade which appears as a serious shortcoming. Especially with the current emphasis on formative and continuous evaluation, student feedback becomes mandatory, especially to reduce unnecessary emphasis on Final Examinations. A yet another important aspect

Table 4: Performance of Departments of study evaluated as Unsatisfactory by Aspect

\begin{tabular}{lll}
\hline $\mathbf{1}$ - Curriculum design, content and review & & \\
\hline University & Faculty & Dept./s \\
Rajarata & Agriculture & Soil \& Water Resources \\
OUSL & Natural Sciences & Physics \\
$\mathbf{2}$ & $\mathbf{2}$ & $\mathbf{2}$ \\
\hline $\mathbf{2}$ - Teaching, Learning and Assessment Methods & \\
\hline University & Faculty & Depts. \\
Jaffna & Medicine & All Medical Depts. \\
$\mathbf{1}$ & $\mathbf{1}$ & -- \\
\hline $\mathbf{3}$ - Quality of Students, including Student Progress and Achievement & \\
\hline University & Faculty & Depts. \\
$\mathbf{0 0}$ & $\mathbf{0 0}$ & $\mathbf{0 0}$ \\
\hline $\mathbf{4}$ - Extent \& Use of Student Feedback, Qualitative \& Quantitative & \\
\hline University & Faculty & Depts. \\
Colombo & Arts & Journalism \\
Peradeniya & Dental Science & Prosthetic Dentistry \\
& & Restorative Dentistry
\end{tabular}

continued - 
- continued from page 8

Sri Jayewardenepura

Kelaniya

Jaffna

Rajarata

07

5 - Postgraduate Studies

University

Colombo

Peradeniya

Sri Jayewardenepura

Jaffna

Vavuniya Campus

Ruhuna

Eastern University
Science

Social Sciences

Agriculture

Science

Arts

Management \& Finance

Science

Arts \& Culture

Social Science \& Humanities

13

Faculties

Science

Arts

Sri Palee Campus

Vet Medicine

Medicine

Engineering

Arts

Agriculture

Science

Arts

Business Studies

Applied Sciences

Agriculture

Humanities \& Social Sciences

Management \& Finance

Science

Agriculture

Arts \& Culture
Sinhala \& Mass communication

Pali \& Buddhist Studies

Statistics \& Computer science

Sociology

Animal Science

Computer science

Music

Hindu Civilization

Tamil

Marketing Management

Botany

Languages

Humanities

18

Depts.

Mathematics

Demography

Mass Media

Veterinary Pathology

Pharmacology

Computer Engineering

English

Agricultural Biology

Botany

Mathematics \& Statistics

Dance

Economics \& Management

Accountancy \& Finance

Physical Sciences

Soil Science

History

Management \& Entreprenuership

Botany

Physics

Chemistry

Mathematics

Agronomy

Agricultural Economics

Comparative Religion \& Social

Harmony

Islamic Studies

Arabic

Social Sciences

Economics Unit

Hindu Civilization

Fine Arts

continued - 
South-Eastern University

Rajarata

Sabaragamuwa

Wayamba

Open University

12

6 - Peer Observation

University

Colombo
Management

Arts \& Culture

Applied Sciences

Agriculture

Applied Sciences

Agricultural Sciences

Management

Applied Sciences

Social Science \& Languages

Geomatics

Applied Sciences

Agricultural \& Plantation Management

Livestock, Fisheries \& Nutrition

Natural Sciences

32

Faculties

Education

Arts

Sri Palee Campus

Dental Science

Vet Medicine

Medicine
Management

Accountancy \& Finance

Social Sciences

Languages

Physical Sciences

Biological Sciences

Mathematical Sciences

Agricultural systems

Agricultural systems

Biological Sciences

Export Agriculture

Livestock Production

Business Management

Physical Sciences \& Technology

Food Science \& Technology

Languages \& English Language

Surveying \& Geodesy

Cartography, etc.

Mathematical Sciences

Computer sciences \& IT

Biotechnology

Avian Sciences

Botany

53

Depts.

Humanities Ed.

Social Sciences Ed.

English

Geography

Journalism

Demography

Sinhala

Political Science

Mass Media

Performing Arts

Basic Science

Oral Medicine

Restorative Dentistry

Basic Vet. Science

Veterinary Pathology

Farm Animal Protection

Veterinary Public Health \& Pharmacology

Veterinary Clinical Sciences

Forensic Medicine

Pharmacology

Anatomy

Community Medicine 
Bio-Chemistry

Science

Arts

Sri Jayewardenepura

Jaffna

Eastern University

South-Eastern University

Rajarata

Wayamba

Arts

Science

Arts

Science
Sabaragamuwa

Medicine

Humanities

Social Sciences

Agriculture

Medicine

Humanities \& Social Sciences

Agriculture

Management \& Finance

Agriculture

Commerce \& Management

Arts \& Culture

Arts \& Culture

Applied Sciences

Social Science \& Humanities

Management

Applied Sciences

Applied Sciences

Business Studies \& Finance

Natural Sciences

Humanities \& Social Sciences

12

7 - Skill Development

University

Peradeniya
32

Faculties

Medicine
Chemistry

Sociology

Sociology \& Anthropology

Sinhala \& Mass communication

English

Medicine

Statistics \& Computer Science

English

Fine Arts- Visual Arts, Design \&

Performing Arts

Sanskrit

Philosophy

Sociology

Animal Science

Geography

Linguistics \& English

Music

Dance

Tamil

All Depts

Mathematics

Sinhala

Animal Science

Management \& Entreprenuership

Agronomy

Economics

Commerce

Languages

Geography

Social Sciences

Physical Sciences

Biological Sciences

Humanities

Tourism Management

Food Science \& Technology

Mathematical Sciences

Banking \& Finance

Insurance \&Valuation

Accountancy

Business Management

Botany

Health Science

Language Studies

65

Depts.

Forensic medicine 


\begin{tabular}{|c|c|c|}
\hline Kelaniya & Humanities & Fine Arts- Drama \& Theatre \\
\hline Jaffna & Arts & Christian \& Islamic Civilization \\
\hline Ruhuna & Humanities \& Social Sciences & Sociology \\
\hline \multirow[t]{2}{*}{ Eastern } & Arts \& Culture & Islamic Studies \\
\hline & & Arabic \\
\hline \multirow[t]{2}{*}{ Wayamba } & Business Studies \& Finance & Banking \& Finance \\
\hline & & Accountancy \\
\hline 6 & 6 & 8 \\
\hline \multicolumn{3}{|c|}{8 - Academic Guidance and Counselling } \\
\hline University & Faculties & Depts. \\
\hline Colombo & Education & Social Sciences Ed. \\
\hline Peradeniya & Dental Science & Prosthetic Dentistry \\
\hline \multirow[t]{2}{*}{ Sri Jayewardenepura } & Arts & Pali\& Buddhist Studies \\
\hline & Management Studies \& Commerce & IT \\
\hline \multirow[t]{2}{*}{ Jaffna } & Science & Computer Science \\
\hline & Arts & Hindu Civilization \\
\hline Vavuniya Campus & Applied Sciences & Biological Sciences \\
\hline \multirow[t]{2}{*}{ Ruhuna } & Science & Botany \\
\hline & Management \& Finance & Marketing Management \\
\hline \multirow[t]{2}{*}{ Eastern } & Arts \& Culture & Geography \\
\hline & & Social Sciences \\
\hline Sabaragamuwa & Management & $\begin{array}{l}\text { Accountancy \& Financial Man- } \\
\text { agement }\end{array}$ \\
\hline Wayamba & Business Studies \& Finance & Business Management \\
\hline OUSL & Education & Special Needs Education \\
\hline 10 & 13 & 14 \\
\hline
\end{tabular}

is Academic Guidance and Counselling, for which 14 Departments in 13 Faculties from ten universities have been given $\mathrm{C}$, an unsatisfactory grade. Such a situation can only occur if the teaching staff has not been properly oriented to their role as teachers, as academic guidance and counselling is an integral component of teaching. Similarly, Peer Observation is valued for its contribution to the improvement of teaching. Academics can gain insights and perspectives from colleagues by observation of their teaching and the process can benefit both the observer and the observee. What is disappointing is to note that 65 Departments in 32 Faculties from 12 universities have been given $\mathrm{C}$, an unsatisfactory grade, on the aspect of Peer Observation. Twenty-eight of these 65 Departments are from Arts-oriented Faculties, nine from Science Faculties and eight from Management Faculties.

Finally, Subject Reviewers had identified 53 Departments in 32 Faculties from 12 universities as Unsatisfactory with regard to Postgraduate Studies. Here it may be useful for the Quality Assurance Council to re-consider whether Faculties rather than Departments of Study should be evaluated in respect of Postgraduate Studies. This is because primarily Postgraduate Studies are offered either by Faculties of Graduate Studies or other Faculties as Faculty Programmes rather than as Departmental programmes.

Overall, institutional reviews portray a positive scenario with the majority of the universities being on the way to improve their quality. In the midst of persistent issues related to the eight aspects evaluated, several good practices could also be identified.

\section{GOOD PRACTICES}

\section{University of Colombo-University Goals and Corporate Planning}

A well-developed exemplary Corporate Plan (20082012) is available for the University. A revised Vision and a Mission along with goals and objectives and suitable strategies have been formulated and implemented. It was learnt that there has been much participation and inputs from the Faculties and Departments in order to make this 
Corporate Plan a success. The Goals and Objectives are mostly achievable. The Corporate Plan in printed form was very comprehensive and detailed. Annual action plans with specific time frames are prepared and required funds are provided along with clear responsibilities assigned to respective officers.

\section{University of Colombo - Financial Resources \& Management}

Both Financial Resources and Management and Quality Management and Administration are addressed under Goal No. 7 in the Corporate Plan (2008-2012). There are four clearly mentioned objectives along with 15 strategies to be implemented in achieving these goals and objectives with clear responsibilities assigned to respective officers. Clear financial policies and procedures are adopted and followed in relation to these activities.

The University gets funds from three main sources, namely;

1. The Consolidated Fund (CF) from the General Treasury

2. Local and Foreign Donor Agencies, IRQUE Project, and Research grants etc.

3. Funds generated through Extension/Fee Levying Programs conducted by the Faculties, institutes, campus and Units functioning under the university

\section{University of Colombo - Research}

The University has provided the infrastructure needed for research. In turn, the members of the academic staff have utilised the facilities made available by the institution. A large number of research publications of the academic staff members in the various Faculties have been published in peer reviewed journals. According to the SER, the total number of papers published in peer reviewed journals during the past five years was 1,087 of which 578 and 509 were in local and international journals, respectively. The total number of citations of publications during past five years was 1,101 averaging at 2.3 citations per member and 0.98 citations per paper. A number of staff members have received awards of excellence in research e.g., Presidential Awards, Ministry of Science and Technology ACU Awards and CVCD Awards.

\section{University of Peradeniya - University/ Industry/ Community/Other extensions activities}

Ten Centres/Units, as mentioned below, operate in the university carrying out specific academic and professional activities assigned to them.
- Agribusiness Centre

- Agricultural Biotechnology Centre

- Institute for the Study of English

- Centre for Continuing Education and Extension Education

- Centre for Environmental Studies

- Centre for Information Technology

- Centre for Regional Tropical Medicine

- Centre for Research and Buddhist Studies

- $\quad$ Engineering Design Centre

- $\quad$ Staff Development Centre

They are intended to provide extension services to both industry and community through undertaking research and training in solving applied problems and undertaking specific assignments.

\section{University of Moratuwa - Learning Resources and Student Support}

The Team considers pooling of lecture rooms and other facilities and making them available across all Faculties as a very good practice. This would lead to optimum utilisation of this scarce resource.

The Library provides an effective service with online journal facilities, extended library hours, multiple copies of recommended textbooks, self-study space and automated check out facilities. Students may submit lists of books required for their studies directly to the library. The ground floor reading room of the library is kept open till 10 p.m., which is a significant benefit for the students who do not get residential facilities at or near the campus. IT infrastructure is available in the University in the Computer Department, Centre for IT services, departmental computer laboratories and at the Library. The university has a comprehensive policy on the provision of computing facilities formulated by the University Computer Policy Committee.

\section{University of Ruhuna - Quality Assurance}

All the Departments of established Faculties and the library have completed the quality assurance reviews and have received the reports. The Vice Chancellor has taken steps to request the Deans to have QA matters as an agenda item at the Faculty Board meetings and specifically take up matters needing improvement indicated in the QA review reports that have been received. Further, the specific plans and requests of Departments to implement the recommendations for improvement have been forwarded to the Vice Chancellor by many Departments, 
but not all. Good practices that are in place have been documented by the different Departments and have been sent to the VC.

\section{CONCLUDING REMARKS}

The author has attempted to peruse the Institutional and Subject reviews carried out by the Review Teams appointed by the Quality Assurance Agency of Sri Lanka in order to improve the quality of university education. The analysis presented may not be totally accurate, especially in the case of Institutional Reviews as specific evaluations have not been made in respect of each aspect. It is commendable that out of the 15 available institutional Reviews (excluding University of Jaffna) 12 have been accorded 'Confidence'.

Analysis of the Subject Review Reports indicate that, on the whole, the Departments in universities have performed satisfactorily, obtaining A grades for half the courses and B grades for $41 \%$ of courses. Not only the older Universities such as Moratuwa, Sri Jayewardenepura, Peradeniya, Kelaniya, Colombo, Ruhuna, but also the newer universities such as Wayamba, Vavuniya Campus, have received a higher percentage of A grades for their courses. However, the concern is that SouthEastern University, Jaffna and Eastern University have received a lower percentage of A grades. Thus, Subject Reviews appear to have corroborated the evaluation of Institutional Reviews.

It is commendable that the three aspects of Quality of Students, including student progress and achievement, Curriculum design, content and review have received very few unsatisfactory grades. The situation is more disconcerting in aspects directly impinging on teachinglearning such as Extent and Use of Student Feedback: Qualitative and Quantitative, Peer Observation and Academic Guidance and Counselling, in which performance of some of the Departments has been adjudged to be unsatisfactory.

Performance has been evaluated also as rather unsatisfactory but it is not verifiable whether Skills had been construed purely as psycho-motor skills, without taking into consideration, other academic skills such as Communication, Planning and Organization and Problem-solving and Decision-making which are indisputably "Skills" which need to be developed through University education as Arts-oriented Faculties seem to have performed poorly.

It may also be useful for the Quality Assurance Council to re-consider whether Departments of Study or Faculties should be evaluated in respect of Postgraduate Studies as they are often offered at the Faculty level.
As has been re-iterated again and again, External Reviews can contribute only to a certain extent to improve quality. These Reviews need to be seriously discussed at Faculty Boards and Senates and progress monitoring be maintained if the desirable outcome is to be achieved.

\section{REFERENCES}

Asian Development Bank (2000) Advancing knowledge and skills for development and competitiveness: The tertiary education strategy for Sri Lanka (Development Forum- Paris 2000), Colombo: Asian Development Bank.

Asian Development Bank (2003) Distance Education Modernization Project - Sri Lanka [Online] Available from: https://www.adb.org/projects/33251-013/main\#projectoverview [Accessed: $30^{\text {th }}$ September 2015]

Clark, B. (1996) Substantive growth and innovative organization, Higher Education, 32, pp:417-30.

DOI: https://doi.org/10.1007/BF00133256

Diaco, E., Hughes, A. and McKelvey, M. (2012) Universities as strategic actors in the Knowledge Economy, Cambridge Journal of Economics, 36, pp: 525-541

DOI: https://doi.org/10.1093/cje/bes024

Drucker, P. (October, 1999) Beyond the Information Revolution, Atlantic Monthly [Online] Available from: https:// www.theatlantic.com/magazine/archive/1999/10/beyond-theinformation-revolution/304658/ [Accessed: 30 ${ }^{\text {th }}$ September 2015].

Graz Declaration on Committing Universities to Sustainable Development [Online] Available from: http://iau-hesd.net/sites/ default/files/documents/graz_declaration.pdf [Accessed: $05^{\text {th }}$ April 2009].

Holm-Nielsen, Lauritz B. (2001) Challenges for Higher Education Systems [Online] Available from: http://siteresources.worldbank.org/EDUCATION/ Resources/278200-109079877269/547664-1099079956815/ ChalengesforhigheredsystemsEn01.pfd. [Accessed: 02 ${ }^{\text {nd }}$ May 2009]

National Conference of State Legislatures (NCSL) (2006) Transforming Higher Education: National Imperative and State Responsibility, Washington, DC.

Salmi, J. (2009) The challenge of establishing world class universities [Online] Available from: http:// siteresources.worldbank.org/EDUCATION/rces/278200$1099079877269 / 547664$ - $1099079956815 / 547670$ 1237305262556/WCU.pdf [Accessed: 27 ${ }^{\text {th }}$ September 2010] 
Washington, DC: The World Bank.

DOI: https://doi.org/10.1596/978-0-8213-7865-6

Sri Lanka, IRQUE Project, Improving quality and relevance of undergraduate education. [Online] Available from: http:// www.irque.lk [Accessed: 16 ${ }^{\text {th }}$ April 2009].

Sri Lanka, University Grants Commission (2013) Internal Quality Assurance Mechanism for Sri Lankan Universities, Colombo.
The United Kingdom, Department for Business Innovation and Skills (2008) The future of universities in a knowledge Economy. [Online] Available from: http://www.ed.ac.uk/ files/atoms/files/bis-higherambitions-summary-nov2009.pdf [Accessed: $30^{\text {th }}$ September 2015]

The World Bank (2012) Knowledge Assessment Methodology [Online] Available from: https://knoema.com/WBKEI2013/ knowledge-economy-index-world-bank-2012 [Accessed: 30 ${ }^{\text {th }}$ September 2015]

\section{APPENDIX}

Table I: Evaluation of universities under Institutional Reviews

\begin{tabular}{|c|c|c|c|}
\hline Aspect & Universities considered as strong & $\begin{array}{l}\text { Universities considered as } \\
\text { needing improvement }\end{array}$ & $\begin{array}{l}\text { Universities for } \\
\text { which the aspect is } \\
\text { not relevant }\end{array}$ \\
\hline $\begin{array}{l}\text { University Goals and } \\
\text { Corporate planning }\end{array}$ & $\begin{array}{l}\text { Moratuwa, Colombo, } \\
\text { Open University, Ruhuna, Sabaragamuwa, } \\
\text { Uva-Wellassa (6) }\end{array}$ & $\begin{array}{l}\text { Kelaniya, } \\
\text { Sri Jayawardenepura, } \\
\text { Peradeniya, Rajarata, Eastern, } \\
\text { South-Eastern, Wayamba, } \\
\text { Visual \& Performing Arts }\end{array}$ & \\
\hline $\begin{array}{l}\text { Financial Resources and } \\
\text { Management }\end{array}$ & $\begin{array}{l}\text { Colombo, Open University, Ruhuna, } \\
\text { Sabaragamuwa, Wayamba, Gampaha WAI (6) }\end{array}$ & $\begin{array}{l}\text { Moratuwa, Kelaniya, } \\
\text { Sri Jayewardenepura, Peradeniya, } \\
\text { Rajarata, Uva-Wellassa, Eastern, } \\
\text { South-Eastern, Visual \& } \\
\text { Performing Arts (9) }\end{array}$ & \\
\hline Research & $\begin{array}{l}\text { Colombo, Moratuwa, Kelaniya, } \\
\text { Sri Jayewardenepura, Peradeniya, Ruhuna, } \\
\text { Sabaragamuwa (7) }\end{array}$ & $\begin{array}{l}\text { Open University, Rajarata, Uva- } \\
\text { Wellassa, Eastern, South-Eastern, } \\
\text { Wayamba, Visual \& Performing } \\
\text { Arts, Gampaha WAI (8) }\end{array}$ & \\
\hline $\begin{array}{l}\text { Quality Management \& } \\
\text { Administration }\end{array}$ & $\begin{array}{l}\text { Moratuwa, Kelaniya, } \\
\text { Sri Jayewardenepura, Ruhuna,Uva-Wellassa, } \\
\text { Wayamba, Visual \& Performing Arts, Gampaha } \\
\text { WAI (8) }\end{array}$ & $\begin{array}{l}\text { Colombo, Peradeniya, } \\
\text { Open University, Rajarata, } \\
\text { Sabaragamuwa, } \\
\text { South-Eastern, Eastern (7) }\end{array}$ & \\
\hline Quality Assurance & $\begin{array}{l}\text { Moratuwa, Colombo, Kelaniya, } \\
\text { Sri Jayewardenepura, Peradeniya, Rajarata, } \\
\text { Ruhuna, Uva-Wellassa, South-Eastern, Wayamba, } \\
\text { Visual \& Performing Arts, Gampaha WAI (12) }\end{array}$ & $\begin{array}{l}\text { Open University, Sabaragamuwa, } \\
\text { Eastern (3) }\end{array}$ & \\
\hline $\begin{array}{l}\text { Learning Resources \& } \\
\text { Student Support }\end{array}$ & $\begin{array}{l}\text { Kelaniya, Sri Jayewardenepura, Peradeniya, } \\
\text { Rajarata, Ruhuna, Sabaragamuwa, Uva-Wellassa, } \\
\text { Wayamba, Gampaha WAI(9) }\end{array}$ & $\begin{array}{l}\text { Moratuwa, Colombo, } \\
\text { Open University, Eastern, South- } \\
\text { Eastern, Visual \& Performing } \\
\text { Arts (6) }\end{array}$ & \\
\hline External Degree Programmes & $\begin{array}{l}\text { Colombo, Peradeniya, Rajarata, Ruhuna, } \\
\text { Sabaragamuwa, Eastern, Wayamba, Gampaha } \\
\text { WAI (8) }\end{array}$ & $\begin{array}{l}\text { Kelaniya, Sri Jayawardenepura, } \\
\text { South-Eastern (3) }\end{array}$ & $\begin{array}{l}\text { Moratuwa, } \\
\text { Open University, } \\
\text { Uva-Wellassa, } \\
\text { Visual \& } \\
\text { Performing Arts (4) }\end{array}$ \\
\hline $\begin{array}{l}\text { University/Industry/ } \\
\text { Community/Other Extension } \\
\text { Activities }\end{array}$ & $\begin{array}{l}\text { Colombo, Kelaniya, Moratuwa, } \\
\text { Sri Jayewardenepura, Peradeniya, } \\
\text { Open University, Rajarata, Ruhuna, } \\
\text { Sabaragamuwa, Uva-Wellassa, } \\
\text { South-Eastern, Wayamba, } \\
\text { Gampaha WAI (13) }\end{array}$ & $\begin{array}{l}\text { Eastern, Visual \& Performing } \\
\text { Arts (2) }\end{array}$ & \\
\hline
\end{tabular}

